\title{
INCIDENCE, RISK FACTORS AND MICROORGANISMS FOR POST CAESAREAN SURGICAL SITE INFECTION IN A TERTIARY CARE CENTRE IN BANGLADESH
}

\author{
MEHZABIN $\mathrm{S}^{1}$, ELAHI MM ${ }^{2}$, BAR D $^{3}$, SINHA B ${ }^{4}$, AKTER T ${ }^{5}$, ALAM MN $^{6}$
}

\begin{abstract}
Background: Surgical site infection (SSI) is a common complication following caesarean section (C-section) and mainly responsible for increased maternal morbidity and higher treatment costs. This study will determine the incidence and risk factors of surgical site infections following caesarean section in Dhaka Medical College Hospital (DMCH).

Materials and Methods: This is a retrospective observational study which was conducted among patients having post caesarean surgical site infections attending post-natal outdoor clinic of DMCH from January, 2019 to December, 2019. Data were collected in structured questionnaire. Culturebased microbiological methods were used to identify causal agents in postoperative wounds.

Results: Overall SSI rate following caesarian section was 4.44\%.Patient related risk factors were inadequate antenatal check-up, emergency procedures, malnutrition (22.44\%), anaemia (21.46\%) associated comorbidity (59.46\%), history of rupture membrane $>12$ hours (40.98\%) and had history of prolonged labour pain $>12$ hours (16.10\%). Surgery related risk factors were repeated per vaginal examinations by untrained birth attendant $(21.95 \%)$ \& duration of surgery $>1$ hour (62.93\%). The most common organisms responsible for SSI were Staphylococcus aureus 44(21.46\%) and Escherichia coli 31(15.12\%). The most sensitive antibiotics were aminoglycosides, cephalosporin \& cloxacillin.

Conclusion: Most of the risk factors for surgical site infection following caesarean section identified in this study can be modified through intervention. However the microorganisms detected from our patient showed a high degree of resistance for commonly prescribed antimicrobials in our set-up.
\end{abstract}

Key words: Surgical site infection; Microorganisms; Risk factors.

J Dhaka Med Coll. 2019; 28(2): 136-141

\section{Introduction}

Caesarean section (CS) is the most common surgical procedure performed on women in both developed and developing countries.Globally, the CS rate is $15 \% .{ }^{1}$ One of the most common complications associated with caesarean section is Surgical Site Infection (SSI) being diagnosed in 2.5 to $16 \%$ of cases. ${ }^{2}$ Caesarean section wound infection represents a substantial burden to the health system and prevention of such infections should be a health care priority in developing countries. ${ }^{3}$

Some of the risk factors observed for CS wound infections, specifically those related to patient's factors include: lack of antenatal care, multiple pregnancies, history of previous C-section, chorioamnionitis, prolonged rupture of membrane and history of prolonged labour. Factors related to surgical procedure include: prolonged surgery, lack of pre-incision antimicrobial care \& massive blood loss during surgery. ${ }^{4}$ Pre-existing morbidities associated with SSI include: obesity, under nutrition, smoking, blood transfusion, diabetes mellitus, hypertension, immunosuppressive therapy, immune incompetence and longer preoperative hospitalization. ${ }^{5}$ SSIs are associated with significant morbidity and occasional mortality,

1. Dr. Shahfinaz Mehzabin, Medical officer, Sheikh Hasina National Institute of Burn and Plastic Surgery

2. Dr. Mohmmad Mahbub Elahi, Resident Surgeon, Dhaka Medical College Hospital

3. Dr. Debashish Bar, Registrar, Department of Surgery, Dhaka Medical College Hospital

4. Dr. Banalata Sinha, Senior Consultant, Model Family Planning Clinic, DMCH

5. Dr. Tahmina Akter, Medical Officer, Model Family Planning Clinic, DMCH

6. Dr. Md. Nur Alam, Indoor Medical Officer, Department of Hepatology, Dhaka Medical College, Dhaka

Correspondence: Dr. Shafinaz Mehzabin, Medical Officer, Sheikh Hasina National Institute of Burn and Plastic Surgery, Mob no: 01711206469

Received: 11-03-2020

Revision: 25-03-2020

Accepted: 21-04-2020 
higher rates of patient's dissatisfaction, prolonged hospital stay, often needs readmission and adds $10-20 \%$ of extra hospital cost. ${ }^{6}$

Although total elimination of SSI is not possible, the delivery of high quality services with early interventions to reduce wound infections is an important aspect of patient safety measures. Therefore, the aim of this study was to determine the incidence of SSIs in patients undergoing CS at Dhaka Medical College Hospital in Bangladesh, to identify risk factors, common bacterial pathogens and antibiotic sensitivity.

\section{Materials and Methods:}

This retrospective observational study was conducted among patients having post caesarean surgical site infections attending post-natal outdoor clinic of Dhaka Medical College Hospital from January, 2019 to December, 2019. The patients who developed SSI after C-section that underwent in the same hospital, diagnosed during their post natal visit, were included in the study irrespective of indications. Patients whose C-section underwent out of $\mathrm{DMCH}$ were excluded from the study. Data were collected in structured questionnaire on the variables responsible for the development of SSI following C-section. Discharge was collected from the surgical incision site with sterile cotton swabs. Culturebased microbiological methods were used to identify causal agents in postoperative wounds. Categorical variables were summarized by frequency (percentage).

\section{Results:}

During the study period $7461 \mathrm{C}$-section were done in DMCH. Among them 331 cases (4.44\%) developed surgical site infection. Among these 331 cases, 205 cases (study population) were diagnosed during their postnatal visits and 53 of them needed readmission. Remaining 126 cases were diagnosed during their hospital stay. Total 179 cases $(2.4 \%)$ needed secondary sutures. Out of these 205 cases who attended post natal outdoor clinic, 184 (89.75\%) had undergone emergency caesarean whereas 21 $(10.25 \%)$ had elective procedure. The age of the patients of this study ranged from 16-40 years, majority of them $(33.17 \%)$ were between 21 to 25 years of age.
Table I

Indications for caesarean sections. ( $N=205)$

\begin{tabular}{lcc}
\hline Indications & Number & Percentage \\
\hline Previous CS & 81 & 39.51 \\
Fetal distress & 64 & 31.21 \\
Prolonged labour & 15 & 07.31 \\
Obstructed labour & 16 & 07.81 \\
Failed induction & 13 & 06.34 \\
Antepartum haemorrhage & 27 & 13.17 \\
Medical disorders & 21 & 10.24 \\
PROM with chorioamnionitis & 05 & 02.44 \\
Malpresentation & 09 & 04.39 \\
Cephalo pelvic disproportion & 17 & 08.29 \\
Severe oligohydramnios & 06 & 02.92 \\
Mother's request & 04 & 01.95 \\
\hline
\end{tabular}

Table II

Patient related risk factors for post caesarean SSI.

\begin{tabular}{|c|c|c|}
\hline Characteristics & Number & Percentage \\
\hline \multicolumn{3}{|l|}{ Parity } \\
\hline 1 & 109 & 53.17 \\
\hline 2 & 55 & 26.83 \\
\hline$>2$ & 41 & 20 \\
\hline \multicolumn{3}{|l|}{ Gestational age in weeks } \\
\hline Preterm (<37 weeks) & 36 & 17.56 \\
\hline Term (37-42 weeks) & 157 & 76.59 \\
\hline Post term (>42 weeks) & 12 & 5.85 \\
\hline \multicolumn{3}{|l|}{ Antenatal check up } \\
\hline Regular (4 or more) & 43 & 20.98 \\
\hline Irregular ( 1-3) & 144 & 70.24 \\
\hline No check up & 18 & 8.78 \\
\hline \multicolumn{3}{|l|}{ Nutritional status (BMI) } \\
\hline Underweight $(<18.5)$ & 24 & 11.71 \\
\hline Normal weight (18.5-24.9) & 159 & 77.56 \\
\hline Overweight (>24.9) & 22 & 10.73 \\
\hline \multicolumn{3}{|l|}{ Medical disorders } \\
\hline Hypertension & 53 & 25.85 \\
\hline Diabetes & 33 & 16.10 \\
\hline Infection present elsewhere & 8 & 3.90 \\
\hline Asthma & 5 & 2.44 \\
\hline Anemia $(\mathrm{Hb}$ level < $10 \mathrm{gm} / \mathrm{dl})$ & l) 44 & 21.46 \\
\hline
\end{tabular}


Most of the patient related risk factors (Table II) were primiparous $(53.17 \%)$, term gestations (76.59\%), malnutrition including both under nutrition (11.71\%) and over nutrition (10.73\%), having anaemia $(21.46 \%)$ that is haemoglobin level $<60 \%$, associated comorbidity (59.46\%) like Diabetes mellitus, HTN, Preeclampsia, infections in other site \& asthma. Few women had more than one medical disorders simultaneously. Among all SSIs $70.24 \%$ had inadequate $88.78 \%$ had no antenatal check-up.

Surgery related risk factors for the development of SSI are repeated per vaginal examinations done by untrained birth attendant $(21.95 \%)$, history of ruptured membrane $>12$ hours $(40.98 \%)$, history of prolonged labour pain $>12$ hours $(16.10 \%)$, patients operated for repeat caesarean section or fetal indications, surgery time $>1$ hour (62.93\%) and patients having drain tube in situ $(21.46 \%)$. Emergency procedures were $184(89.75 \%)$ which were more likely to develop SSI as compared to elective caesarean $21(10.25 \%)$.

The majority of SSI cases yielded growth of Staphylococcus aureus (44, 21.46\%) followed by Escherichia coli (31, 15.12\%) [Table IV]. Polymicrobial infections were found in 7 (3.41\%) cases. The main organisms found to be grown together were: klebsiella and E. coli, Klebsiella and S. aureus, Klebsiella and Proteus, E. coliand Proteus; and E. coli and coagulase negative $S$. aureus. There were 74 (36.10\%) cases where the culture did not yield any organisms probably due to the use of broad spectrum antibiotics prior to the wound swab. Other organisms that were isolated were Acinetobacter 14(6.83\%), Pseudomonas 13(6.34\%), Proteus 8(3.9\%) and Klebsiella 7(3.41\%).

Table III

Labour and surgery related risk factors for post caesarean SSI.

\begin{tabular}{|c|c|c|}
\hline Labour and surgery related factors & Number & Percentage $(\%)$ \\
\hline Duration of ruptured membranes in hours & 119 & 58.05 \\
\hline$<12$ hours & 35 & 17.07 \\
\hline$>12$ hours & 84 & 40.98 \\
\hline Intact membrane & 86 & 41.95 \\
\hline \multicolumn{3}{|l|}{ Number of vaginal examinations } \\
\hline d"3 & 160 & 78.05 \\
\hline$>3$ & 45 & 21.95 \\
\hline \multicolumn{3}{|l|}{ Duration of labour in hours } \\
\hline$<12$ hours & 103 & 50.24 \\
\hline$>12$ hours & 33 & 16.10 \\
\hline Nolabour pain & 69 & 33.66 \\
\hline \multicolumn{3}{|l|}{ Intervention by untrained dai } \\
\hline intervention & 43 & 20.98 \\
\hline No intervention & 162 & 79.02 \\
\hline \multicolumn{3}{|l|}{ Duration of surgery } \\
\hline$<1$ hour & 76 & 37.07 \\
\hline$>1$ hour & 129 & 62.93 \\
\hline \multicolumn{3}{|l|}{ Use of drain } \\
\hline Yes & 44 & 21.46 \\
\hline No & 161 & 78.54 \\
\hline \multicolumn{3}{|l|}{ Blood transfusion needed during/after surgery } \\
\hline 1 unit & 29 & 14.15 \\
\hline$>1$ unit & 27 & 13.17 \\
\hline Not needed & 149 & 72.68 \\
\hline \multicolumn{3}{|l|}{ Types of caesarean section } \\
\hline emergency & 184 & 89.75 \\
\hline elective & 21 & 10.25 \\
\hline
\end{tabular}


Table IV

Organisms causing wound infection following C-Section among study group.

\begin{tabular}{|c|c|c|c|c|c|}
\hline $\begin{array}{l}\text { Gram positive } \\
\text { organisms }\end{array}$ & $\mathrm{n}(\%)$ & $\begin{array}{l}\text { Gram negative } \\
\text { organisms }\end{array}$ & $\mathrm{n}(\%)$ & Others & $\mathrm{n}(\%)$ \\
\hline S. aureus & $44(21.46)$ & E. coli & $31(15.12)$ & No growth & $74(36.10)$ \\
\hline \multirow[t]{2}{*}{ MRSA } & $5(2.44)$ & Acinetobacter & $14(6.83)$ & $\begin{array}{l}\text { Mixed growth } \\
\text { (polymicrobial }\end{array}$ & \\
\hline & & & & organisms) & $7(3.41)$ \\
\hline a-H streptococci & $1(0.49)$ & Pseudomonas & $13(6.34)$ & & \\
\hline \multirow[t]{2}{*}{ b-H streptococci } & $1(0.49)$ & Proteus & $8(3.9)$ & & \\
\hline & & Klebsiella & $7(3.41)$ & & \\
\hline
\end{tabular}

Table V

Antibiotics prescribed for post caesarean wound infections according to culture sensitivity $(N=205)$

\begin{tabular}{lcc}
\hline Antibiotic & $\mathrm{N}$ & $\%$ \\
\hline Penicillin, amoxicillin, & 32 & 15.61 \\
ampicillin and co-amoxiclav & & \\
Cloxacillin & 33 & 16.10 \\
Cephalosporin & 41 & 20 \\
Aminoglycoside (gentamicin) & 48 & 23.41 \\
Meropenem & 22 & 10.73 \\
Fusidic acid & 14 & 6.83 \\
Linezolid & 14 & 6.83 \\
Colistin & 1 & 0.49 \\
\hline
\end{tabular}

The aminoglycoside constituted the most sensitive antibiotic and was used whenever indicated by the culture sensitivity [Table V]. Cephalosporin was frequently used as it was the second most sensitive antibiotic of choice. Other groups of drugs showing sensitivity in culture were: cloxacillin $(33,16.10 \%)$, penicillin(32, 15.61\%), meropenem (22, $10.73 \%)$, fusidic acid(14, 6.83\%), linezolid(14, $6.83 \%)$ and colistin(1, 0.49\%). Antibiotics like meropenem, imipenem were used for the Enterobactericeae which were highly resistant to cephalosporin.

\section{Discussion:}

This study evaluated the rate of SSI after CS, determined risk factors for development of SSI and identified the common bacteriological profile in the study population. The rate of CS wound infections was $4.9 \%$ in the current study which was comparable to rates of $2.8 \%$ reported by Mahet $a l^{7} \&$ Mathew et $a l^{8}$ and similar low rates of $2.8 \%$ and $2-5 \%$ in the USA and certain European countries. ${ }^{9}$ High incidence rate upto $48 \%$ is noted in low resource settings in developing countries. These demonstrate that the overall SSI rate differs widely depending upon study sample, preexisting diseases, use of antibiotics as well as reliable methods for SSI documentation and reporting.

The development of SSI is multifactorial and various risk factors have been found for post caesarean SSI. In our study one of the patient related factors is young maternal age $(78.05 \%)$ occurred in women less than 30 years, this is in accordance with other studies. ${ }^{10}$ Most of the patients of this study had inadequate( $70.24 \%)$ or no( $8.78 \%)$ antenatal check up which is consistent with another study done by Killian et $a l^{11}$ in New York in 2001. This is the single most important factor where intervention is mostly effective by good prenatal care and thus preventing most of the risk factors like anemia, hypertension, uncontrolled diabetes, prolonged rupture of membrane and we can avoid many emergency C-sections.

Hypertensive disorders in pregnancy which is linked with chronic alteration in peripheral blood supply have been found to be a risk factor for SSI. ${ }^{12}$ The incidence of infections in patients with diabetes was significantly higher (33, $16.10 \%)$ in this study as uncontrolled blood glucose level increase the infection rate and 
impairs wound healing as it enables the leukocytes to control the harmful proliferation of bacteria. Both obesity and under nutrition have been associated with increased risk of SSI. ${ }^{13}$

Prolonged rupture of membranes ( $>12$ hours), prolonged labour and frequent vaginal examinations $(>3)$ are established risk factors of SSI. ${ }^{14}$ Loss of protective cervical mucus plug and barrier effect of fetal membranes and amniotic fluid after rupture of membranes are thought to be the main cause. Frequent vaginal examinations increases the risk of introduction of infection.

Emergency CS(89.75\%) were more likely to develop SSI as compared to elective CS(10.25\%) due to inadequate preparation time and associated other risk factors. Another risk factor is longer operation time which leads to extensive tissue trauma, desiccation and maceration of wound edges, increase number of bacteria, decreased temperature and hypovolaemia. ${ }^{15}$

In bacteriological study, microorganisms were identified in $63.9 \%$ cases. Staphylococcus aureuswas the most common organism (21.46\%). Other organisms were Escherichia coli (15.12\%), Acinetobactersp (6.83\%), Pseudomonas $s p(6.34 \%)$, Proteus $s p(3.9 \%)$ and Klebsiellasp (3.41\%). Polymicrobial infections were found in $7(3.41 \%)$ cases. In a study done in 2007 by Anguzu $\mathrm{JR}^{16}$ in Uganda, microorganisms were identified in $58.5 \%$ cases and the most common organism was Staphylococcus aureus(45.1\%). Most organisms of our study were sensitive to aminoglycosides, cephalosporin \& cloxacillin. Three cases (one proteus, two pseudomonas) were resistant to all antibiotics. This finding is a real threat to both patients and doctors.

\section{Limitations of the study:}

1. It was a retrospective study.

2. This study was done on the patients who came on post natal visits being referred from different areas of the country. As all the patients might not come for post natal check up in this outdoor, many SSI might not come to our data and the real incidence of SSI may be more than our study.

\section{Conclusions:}

The need to reduce SSI is currently receiving considerable attention and requires more research. Identifying modifiable risk factors in antenatal period, properly managing patients with co-morbidities, ensuring sterile environment, aseptic surgeries, use of antimicrobial prophylaxis and reducing surgery time can decrease further SSI rates. Each hospital authority should ensure standard of infection control and steps should be taken to improve further.

\section{References:}

1. Betrán AP, Merialdi M, Lauer JA, Bing-Shun W, Thomas J, Van Look P et al. Rates of caesarean section: analysis of global, regional and national estimates. Paediatr Perinat Epidemiol 2007; 21(2): 98-113.

2. Owen J, Andrews WW. Wound complications after cesarean sections. Clin Obstet Gynecol. 1994;37:842. https:/ / doi.org/ 10.1097/00003081-19941200000009. PMID: 7842552

3. Nwankwo EO, Ibeh I, Enabulele OI. Incidence and risk factors of surgical site infection in a tertiary health institution in Kano, northwestern Nigeria. Int J Infect Control 2012; 8:1"6. doi: 10.3396/ ijic.v8i4.035.12.

4. National Healthcare Safety Network, Centers for Disease Control and Prevention.Surgical site infection (SSI) event.http://www.cdc.gov/nhsn/pdfs / pscmanual/9pscssicurrent.pdf. Accessed Jan 25 2017

5. Cheadle WG. Risk factors for surgical site infection. Surg Infect. 2006;7(S1):s7-11.

6. Zuarez-Easton S, Zafran N, Garmi G, Salim R. Postcesarean wound infection: prevalence, impact, prevention, and management challenges. Int $\mathrm{J}$ Women's Health. 2017;9:81-8.

7. Mah MW, Pyper AM, Oni GA, Memish ZA. Impact of antibiotic prophylaxis on wound infection after cesarean section in a situation of expected higher risk. Am J Infect Control 2001; 29:85"8. doi: 10.1067/mic.2001.111372.

8. Mathew M, Kumari R, Vaclavinkova V, Krolikowski A. Caesarean sections at Sultan Qaboos University Hospital: A three year review. J Sci Res Med Sci 2002; 4:29"32.

9. Mahesh CB, Shivakumar S, Suresh BS, Chidanand SP, Vishwanath Y. A prospective study of surgical site infections in a teaching hospital. J ClinDiagn Res 2010; 4:3114"19. 
10. De Nardo P, Gentilotti E, Nguhuni B, Vairo F, Chaula Z, Nicastri E, NassoroMM, Bevilacqua N, Ismail A, Savoldi A, Zumla A. Post-caesarean sectionsurgical site infections at a Tanzanian tertiary hospital: a prospective observational study. J Hosp Infect. 2016;93(4):355-9.

11. Killian CA, Graffunder EM, Vinciguerra TJ, VeneziaRA. Risk factors for surgical-site infections following caesarean section. Infect Control Hosp Epidemiol 2001;22:613-617.

12. Myles TD, Gooch J, Santolaya J: Obesity as an independent risk factor for infectious morbidity who undergo cesarean delivery. Obstet Gynecol. 2002;100(5):959-64. https://doi.org/10.1016/ S0029-7844(02)02323-2. PMID: 12423861

13. Ezechi OC, Edet A, Akinlade H, Gab-Okafor CV, Herbertson E. Incidence and risk factors for cesarean wound infection in Lagos, Nigeria. BMC Res notes. 2009;2(1):186. https://doi.org/10.1186/1756-05002-186. PMID: 19772612.

14. Schneid-Kofman N, Sheiner E, Levy A, Holcberg G. Risk factors for wound infection following cesarean deliveries. Int J Gynecol Obstet 2005;90(1):10-15. https://doi.org/10.1016/j.ijgo.2005.03.020. PMID: 15913620 .

15. Alsaimary IEA. Bacterial wound infections in diabetic patients and their therapeutic implications. Med Pract Rev 2010; 1:12"15.

16. Anguzu JR, Olila D. Drug sensitivity patterns of bacterial isolates from septic post-operative wounds in a regional referral hospital in Uganda, African Health Sciences 2007; 7(3): 148-154. 